\title{
Sexual Abuse: Investigation of Rape, Sodomy, and Murder
}

\author{
Sharon D. Kumar ${ }^{1}$, Vishal Saini ${ }^{2 *}$ \\ ${ }^{1}$ M.Sc Forensic Science, Department of Forensic Science, National Forensic Science University, Gujarat, India \\ ${ }^{2}$ M.Sc Forensic Science, Department of Zoology, Kurukshetra University, Kurukshetra, Haryana, India
}

\begin{abstract}
There are widely increased in sexual abuse that becomes a severe predicament of every society. It has not only put permanent stains on the deceased, but as well as her entire family into degrades and shame. The sensual abuse cases' progressive contribution was being targeted mostly on women, infants, and homosexuals, by the disparate manner of assault-style like sodomy and the killer is male. Sadly, many children become the sufferer of sex-related homicides perpetrated by the individual who are intended to protect them from evil. Four categories of rapists are power reassurance, power assertive, anger retaliatory, and anger excitation. It is necessary to bring justice to society and should fear the consequences the criminals will face. We present a case study that will bring about the important facts and figures of how forensic science helps give conclusions to the cases. In some situations. Offender profiling has been debate on recommending psychiatric and psychological analysis of the sexual offender in such despicable crime.
\end{abstract}

Keywords: Chieloscopy, Forensic evaluation, Medico-legal examination, Physical evidence,POCSO: Protection of Children from Sexual Offence, SAECK: Sexual Assault Evidence Collection Kit.

Int J Eth Trauma Victimology (2020). DOI: 10.18099/ijetv.v6i02.9

\section{INTRODUCTION}

Cexual abuse is a very common obstacle in every society. ${ }^{1}$ It typically includes unwanted and inappropriate sexual solicitation of or exposure to; women mostly are of child which is done by a person through genital touching or fondling or penetration in terms of anal, oral or vaginal intercourse or attempted intercourse. In India, sexual offences are covered in different Indian penal code sections, and it does not distinguish between adult and child victims. In the case of rape, it is a natural offences, which comes under section of 375 , I.P.C.which states that the unlawful sexual activity and any sexual intercourse which is carried out forcibly or under the threat of injury against a person's will or with a person who is beneath a certain age or incapable of valid consent because of mental illness, mental deficiency, intoxication, unconsciousness, or deception. Although, the Protection of Children from Sexual Offences Act (POCSO), 2012, which has been recently drafted to strengthen the legal provisions for the exploitation and protection of children from sexual abuse, defines a child as any person below the age of 18 years and protects all children under the age of 18 years of the offense of sexual assault, sexual harassment, and pornography. There are multiple reasons for the drastic increase in rape cases. The number of unemployment, peer pressure or influence, number of under-aged desires or fantasy and psychological issues is few reasons that can be named. ${ }^{2}$

Women and children all around the world are vulnerable to the most curl form of behavior known as sexual assault. This is the most in a human manner of crime, which is seen to be most injustice. According to the National Crime Records Bureau (NCRB), MHA, Govt. of India report of the year 2017, it is known that every 20 minutes, a woman is raped across the India. About $70 \%$ cases of sexual assault which have been

CIJETV. All rights reserved
Corresponding Author: Vishal Saini, M.Sc Forensic Science, Department of Zoology, Kurukshetra University, Kurukshetra, India, e-mail: vsaini762@gmail.com

How to cite this article: Kumar, S.D., \& Saini, V. Sexual Abuse: Investigation of Rape, Sodomy, and Murder. Int J Eth Trauma Victimology 2020;6(2):35-38.

Source of support: Nil

Conflict of interest: None declared

Received:22/06/2020; $\quad$ Received in revised form: 11/10/2020;

Accepted: 13/10/2020;

Published:25/12/2020

targeted over the infants. The form of sexual attacks is getting intense and tremendous in different ways. ${ }^{3}$

The sexual abuse which is done by unnatural ways, which is called as sodomy, which comes under the section 377 of I.P.C. It is the anal intercourse between two males or between a male and female. ${ }^{4}$ It is called gerontophilia when the passive agent is an adult, and pederasty, when the passive agent is a child, who is known as catamite. Sodomy is a sexual activity that is found to be a strong activity which is found as a strong attack, which are a social as well as a religious crime. It is led by the failure of teeming the disciple of all sorts of sexual desires.

For the proper investigation of murder and rape cases, the investigative officer (I.O.) and forensic team need to be look over the undisturbed crime scene after the incident and start the collection of the shreds of evidence take place to link between the victim, crime scene, and the suspect for the triumphant investigation. They should ensure that they barricade the area and seal the area. Ensure that appropriate evidences are being sent with the proper chain of custody. ${ }^{3}$

\section{7's of crime scene-}

1. Securing the scene

2. Separating the witness 
3. Scanning the scene

4. Seeing the scene

5. Sketching the scene

6. Searching for the evidence

7. Securing and collecting pieces of evidence

\section{These are $^{3}$}

a. Evaluation of the proper timely crime scene management.

b. Videography/sketch of crime scene/record injury on the body and private parts.

c. Collection of the cell phone of victim and the suspect to analyze call records.

d. Type of strangulating materials like rope, wire, dupatta, long cloth etc. which are used during the crime.

e. The strangulation mark on the victim's neck to be recorded with scaled photograph.

f. The collection of biological evidence (vaginal/anal/oral swab) which is registered by medical officer using sexual assault evidence collection kit (SAECK)

g. Seminal constituents on a sexual assault victim are important evidence that sexual intercourse has taken place, but their absence does not necessarily mean that a sexual assault did not occur. Physical injuries such as bruises and bleeding tend to confirm that a violent assault may be occurred. The forceful physical contact between the assailant and the victim may result that a transfer of physical evidence such as blood, semen, hairs, and fibers. The presence of these types of evidences helps us forge a vital link in the chain of circumstances surrounding a sexual crime.

h. Condom used during the assault is collected, if present, and be swabbed separately from the inner and the outer surface. i. The sexual assault victim must undergo a medical examination as soon as possible after the assault; all the outer garments and undergarments from the victim should be carefully removed and packaged separately in paper (not plastic) bags. ${ }^{3}$

\section{Case Report}

On Tuesday, July 11, the nude and battered body of Margaret, a 43-year-old white female, was discovered in the basement of her home by her 21-year-old son, Jeremy. Her daughter, Angela, became concerned when she couldn't reach her mother by phone. She had gone to the house earlier that day. When she did not receive an answer to her knocks on the door, she contacted Jeremy. Jeremy, who had moved out of the house on Friday, July 7, had relocated in an adjoining town, and had a key to the house. Responding to Angela's call, Jeremy went to his mother's house. Using his key, he entered through the back door, which had been locked. He proceeded into his mother's bedroom and found the room in slight disarray with various dresser drawers open. The telephone was on the bed with the cords ripped out. He also noticed that one of the pillowcases from the victim's pillows was missing. He then walked through the house, looking for some note or message from his mother. When he entered the basement area, he discovered his mother's nude body lying on the basement floor with a pillowcase over her head and her hands and feet bound. He immediately realized that she was dead and called 911.5

\section{Police Response}

The initial response to the crime was by the Pontiac Police Department, who subsequently requested the Oakland County Sheriff's Department to assist both in the crime scene process Table 1: Procedure to collect items of physical evidence from the sexual assault victim
Hair around the pubic region

Swab from the genital area

Swabs taken from the outer area of the genial area

Clothing samples

Nail and scratch marks

Blood

Urine

Swabs for patients below 10years

Forensic evidence

The detection of the suspect fluids like saliva, semen or blood stains. There could be bite marks or lip prints and scratch marks around the mouth region.

There can be smothering attempts that could be observed.

There could swabs taken from the skin to find the starch marks, bloodstains, and semen samples around the thigh region, suction marks, bite marks, and bruise marks. These swabs should be taken in 72 hours.

The important technique to collect the semen sample could be done by combing the hair. It can detect impurities and foreign hair samples.

It is important to take within 72 hours; it is taken from the top valve region. It is important to find the presence of semen sample collection as well as the possibility of the sign of penetration in the anal or vagina.

It's important to check the outer area of the anal region; there could bruise observed. Blood and semen samples could be found around the public hair and the buttock regions.

Ensure that luminal is used and cut the region with semen samples are being taken and the swabbed.

The scratch marks are photographed are recorded, and the nail scarped out from the nail bud.

DNA samples collection using FTA card.

With blood sample we can detect the any sort of drug abuse was involved.

The detection of any sexually transmission has occurred.

This is mainly helpful for the detection of the drug abusers if any.

The vaginal is tending to have more blood and internal rupturing. 
and the subsequent major case investigation. The Pontiac Police Department worked jointly with the Oakland County Sheriff's Department on all major crimes. Detective Sergeant William Harvey of the Oakland County Sheriff's Department eventually became the officer in charge of the homicide investigation, which occurred in the City of Pontiac, County of Oakland, in the State of Michigan. ${ }^{3}$

\section{Description of Crime Scene}

The scene was described as a single-story, white house located on the north side of Peacock Street. The victim was described as a white female, later identified as Margaret. Her body was found in the southeast corner area of the basement floor. The victim was lying on her right side. Her body was totally nude, and a multicolored pillowcase had been wrapped around her head and tied at the neck area with a telephone cord. Her hands were tied very tightly with a telephone cord, which had been knotted. Her feet were also tied tightly together with telephone wire. There was a pooling of blood, which appeared to emerge from the head area (Figures 1 and 2). There were also signs of a struggle in the area where the victim's body was lying. The north-side basement window, above a washtub, was found open, and a dark-colored paint chip was found on the basement floor just in front of the washer. The basement wall, just below the opened basement window, had spray-painted on it, which

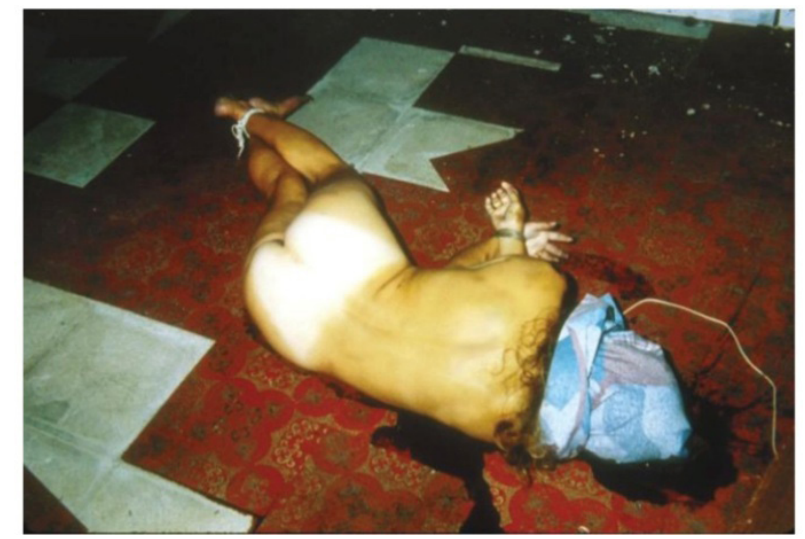

Figure 1: Body at scene. The victim's body was totally nude. Her head was covered with a pillowcase and her hands and feet were bound.

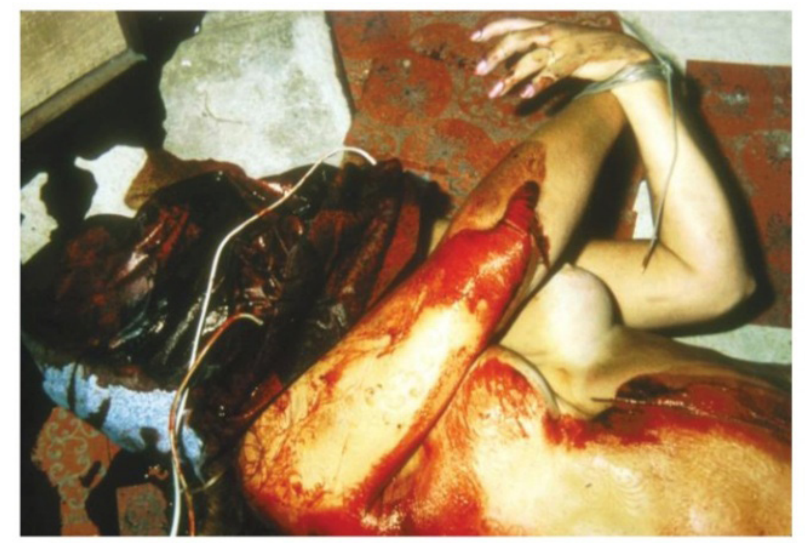

Figure 2: Body examination. The pillowcase on the victim's head was saturated with blood. She had been stomped to death. investigators recognized as some type of gang graffiti. There were also signs of a struggle in the northeast bedroom. ${ }^{6}$

- The phone and answering machine were lying tossed on the bed with their cords removed and/or ripped out.

- There was a brown wallet-type purse on the bed, which appeared to have been dumped onto the bed. The contents were strewn across the sheet.

- There was one pillow missing, a pillowcase at the side of the bed, and another pillow with a multicolored pattern on top of the bed. This matched the pillowcase tied on the victim's head.

- It also appeared that the dresser drawers had been gone through in the northeast bedroom.

- Investigators observed a pair of light-colored flowered panties and a black negligee lying on the bedroom floor next to the bed.

- There was a phone base, missing its cord, which had been apparently ripped from its connection.

The rest of the house was neat and clean with no signs of forced entry except for the basement window. A number of items of evidence were recovered from both the victim's body and the crime scene. Among these items were hairs, including suspected pubic hair, swabs from the victim's buttocks area, blood samples from the crime scene and victim, and hairs and fibers from the basement window. Preliminary examination revealed multiple hair types foreign to the victim. ${ }^{3}$

\section{Autopsy Findings}

An autopsy was conducted on July 12 by a Deputy Chief Medical Examiner for the Oakland County Medical Examiner's office. The cause of death was listed as blunt force head trauma. The autopsy findings are listed as follows (Figure 3).

Blunt force head trauma with

- Abrasions and lacerations on the face

- Extensive subscapular hemorrhage

- $\quad$ Skull fracture

- Bilateral subdural and subarachnoid hemorrhage

- Brain contusions

- Brain edema and herniations

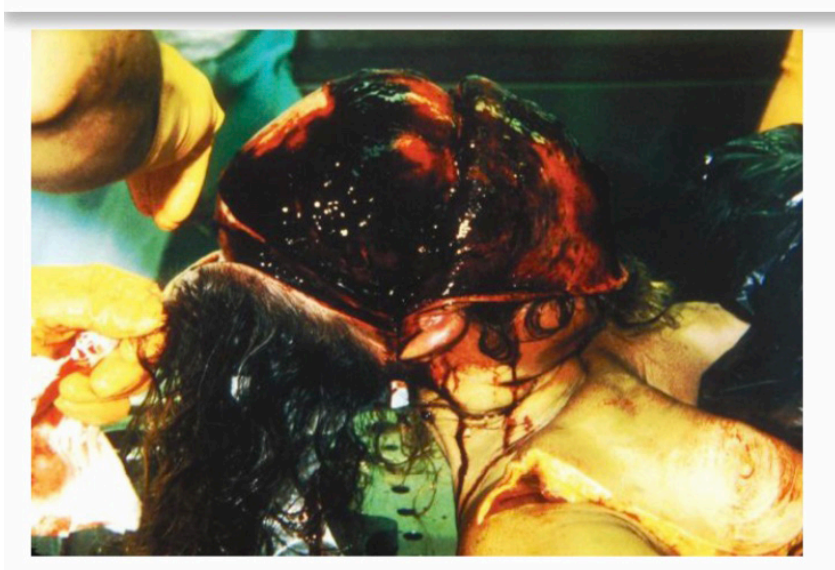

Figure 3: Autopsy photograph. The brain edema and herniation were suggestive of survival following impact on the head. Note a large amount of hemorrhaging. 
- Small focal areas of hemorrhage in the soft tissue of the neck

- Contusions in vagina and anus.

- The vagina had contusions near the introitus as well as on the middle part of the posterior wall of the vagina.

- The anus has contusions all around the external openingabrasions and contusions on the back and extremities.

\section{Opinion}

Margaret died of blunt force head trauma. Although there were small areas of hemorrhage in the soft tissue of the neck, there was no fracture of laryngeal cartilage or hyoid bone and there was no evidence of conjunctival petechiae indicating strangulation. The injuries in the vagina and anus were indicative of sexual assault. The medical examiner further opined that the brain edema and herniation were suggestive of survival following impact on the head. This meant that the victim lay there suffering on the floor for some time after the assault. The manner of death was determined that it may be a homicide. $^{7}$

\section{Conclusion}

Rape is definitely a substantial issue in the community with a lot of political influences, ignoring the victim rights for justice. Thereby, the importance of bringing all the evidence pieces to be a strong close for the victim. It is a justification for the public society with prevention and control of these issues. The cases provided show the stringent requirements for the significance of having forensic science in the legal system. Rape murder is a complicated issue that is found in the present cases. It is unbelievable to perceive under what situation the rapist, after sexual gratification, could kill the girl. However, in such case the accused are required psychiatric analysis to know more about their criminal behavior. The strong limb for the cases with to be brought about is with the significant evidence. Mass communication plays an important to make the number of awareness for society. With the advancement in science, now it's possible to bring the justifications and provide stringent measures day by day. ${ }^{8}$

\section{REFERENCES}

1. Geberth VJ. Sex-related homicide and death investigation: Practical and clinical perspectives. CRC Press; 2010.

2. Irimia R-E, Gottschling M. Taxonomic revision of Rochefortia Sw.(Ehretiaceae, Boraginales). Biodivers Data J. 2016;(4).

3. Kumara SD, Sainib V. Nyayik Vigyan Journal of Forensic Research and Criminal Investigation (NVJFRCI).

4. Hilal MA-E, Said AM, El-sayed WA, Kamel M, Mostafa M. Study of sodomy cases referred to medico legal department/ Ministry of Justice in sohag in the period from January, 2014 to January, 2017. Sohag Med J. 2017;21(3):349-356.

5. Brophy J. Synthesis of research on strategies for motivating students to learn. Educ Leadersh. 1987;45(2):40-48.

6. Harel VS, Khairkar SR, Kulkarni KV, Malve MK. Detection of Semen Stains in Rape Cases by a Very High Powered UV-VIS Light Source, Facilitated Conviction of Accused Person. J Forensic Res. 2015;6(4):1.

7. Savine J, Turvey B. Rape Investigation and Handbook. 2nd ed.

8. Paparo GP, Siegel H. Histologic diagnosis of sodomy. J Forensic Sci. 1979;24(4):772-774. 